\title{
Isı Pompalı İnfrared Kurutucuda Dilimlenmiş Limonun Kurutulmasının Performans Analizi
}

\author{
Simge Pelin ALKAÇ*, ${ }^{*}$, Kurtuluş BORAN ${ }^{\mathrm{a}}$, Mustafa AKTAŞ ${ }^{\mathrm{a}}$, Meltem TOKDEMIR ${ }^{\mathrm{a}}$

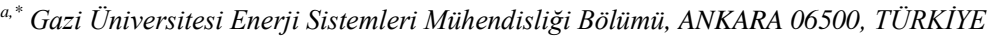 \\ MAKALE \\ BİLGISİ \\ Alınma: 14.05.2019 \\ Kabul: 16.07.2019

\section{Anahtar Kelimeler:} \\ Kurutma, Limon, \\ Bağıl Nem Kontrolü, \\ Is1 Pompası, Kızılötesi \\ *Sorumlu Yazar: \\ e-posta: \\ simgepelinalkac@gma \\ il.com

\section{ÖZET} \\ Bu çalışmada 1sı pompalı infrared bir kurutucuda dilimlenmiş limonun kurutulması deneysel \\ olarak analiz edilmiştir. Deney düzeneği kapalı çevrim ve taze hava girişli olarak iki ayrı şekilde \\ tasarlanmış ve aynı değerlerde deneyler yapılarak taze hava girişi olan ve olmayan sistemin \\ kuruma kinetiğine etkileri karşılaştırılmıştır. $5 \mathrm{~mm}$ kalınlığında dilimlenmiş limonlar 6,6804 g \\ $\mathrm{su} / \mathrm{g}$ kuru madde başlangıç nem miktarından $60^{\circ} \mathrm{C}$ sabit sıcaklıkta ve $595 \mathrm{~m}^{3} / \mathrm{h}$ giriş hava debisi \\ şartlarında $0,045 \mathrm{~g} \mathrm{su} / \mathrm{g}$ kuru madde miktarına kadar kurutulmuştur. Kurutma işlemi kapalı \\ çevrim sistemde 5 saat, taze hava girişli sistemde 6 saat sürmüştür. Literatürdeki çalışmalarda \\ limon dilimlerinin infrared kurutucuda kurutulması incelenmiş ve kurutma ișlemi 8 saat \\ sürmüştür. Yapılan deney sonrasında ortalama COPws değeri taze hava girişli sistem için 2,67, \\ kapalı çevrim sistem için 2,74 olarak bulunmuştur. Yapılan çalışma sonucunda kapalı çevrim \\ sistemin kurutma süresini, taze hava girişli sisteme göre $\% 16,67$ azalttığı tespit edilmiştir. \\ Kurutulan limonların gözle analizi yapıldığında ürün kalitesi açısından iki sistem arasında fark \\ olmadığ1 görülmüştür. Yurtiçi ve yurtdışı pazarda önemli yeri olan limon meyvesinin \\ kurutularak değerlendirilmesinin ülke ekonomisine büyük katkı sağlayacağı düşünülmektedir.
}

\section{Experimental Analysis of Sliced Lemon Drying in Infrared Dryer Which is Supported with Heat Pump}

\section{ARTICLE INFO}

Received: 14.05.2019 Accepted: 16.07.2019

\section{Keywords:}

Drying, Lemon,

Relative Humidity Control, Heat Pump, Infrared.

\begin{tabular}{l} 
"Corresponding \\
\hline Authors \\
e-mail: \\
simgepelinalkac@gma \\
il.com
\end{tabular}

\author{
ABSTRACT
}

In this study, drying sliced lemons with an infrared-heat pump dryer is analyzed. The testing apparatus is designed for two different systems: closed air loop and fresh air inlet. Experiments are competed with same values for both systems and the effects of these systems on drying kinetics are compared. $5 \mathrm{~mm}$ thick sliced lemons are dried from $6,6804 \mathrm{~g}$ water/ g dry matter moisture content to $0,045 \mathrm{~g}$ water/ $\mathrm{g}$ dry matter moisture content at $60^{\circ} \mathrm{C}$ constant temperature and $595 \mathrm{~m}^{3} / \mathrm{h}$ inlet air flow. The drying process completed in 5 hours with closed air loop system and in 6 hours with fresh air inlet system. In the literature studies, drying of the lemon slices in the infrared dryer was examined and drying process completed at 8 hours. The average COPws value calculated as 2,67 for fresh air inlet system and 2,74 for closed air loop system. According to experiments, drying time decreased $16,67 \%$ on closed loop system as against fresh air inlet system. Visual analysis of dried lemons showed no difference between the two systems in terms of product quality. It is considered that evaluating of lemon by drying process which has an important place in the domestic and international markets, will contribute greatly to the economy of the country. 


\section{GİRISŞ (INTRODUCTION)}

Gıda kurutma, gıdaların içerdiği nem miktarının azaltılarak daha uzun süre dayanmalarını sağlamak amacıyla yapılmaktadır. Kurutma işlemi yapılırken kurutulan ürünün besin değerlerinin ve aromatik özelliklerinin de korunması gerekmektedir. Limon içeriğinde yüksek $\mathrm{C}$ vitamini ve antioksidan barındırmaktadır ancak yüksek su ve nemden dolayı uzun süre muhafaza edilememektedir. Aynı zamanda tüm meyve ve sebzelerde olduğu gibi, kurutulmuş limonun da besin/kalori değerleri, aynı miktarda yenilen yaş limonun besin/kalori değerinden daha yüksektir. Limonun kurutularak saklanması, daha uzun süre muhafaza edilmesinde, taşınmasında ve depolanmasında oldukça kolaylık sağlayacak ve bu avatajlar limon ihracatının gelişmesinde olumlu etki yaratacaktır.

International Trade Center verilerine göre Türkiye turunçgil ihracatında ilk 5 'te yer almaktadır. Limon meyvesi de Türkiye ekonomisinde oldukça önemli bir yer tutmaktadır.

TÜİK verilerine göre 2013-2016 yılları arasında Türkiye'deki limon üretim miktarları (ton/yıl) aşağıdaki çizelgede verilmiştir:

Tablo 1. Türkiye'deki Y1llık Limon Üretimi (ton/yıl)

\begin{tabular}{|c|c|c|c|c|}
\hline & $\mathbf{2 0 1 3}$ & $\mathbf{2 0 1 4}$ & $\mathbf{2 0 1 5}$ & $\mathbf{2 0 1 6}$ \\
\hline $\begin{array}{c}\text { Limon } \\
\text { Uretimi }\end{array}$ & 726283 & 725230 & 750550 & 850600 \\
\hline
\end{tabular}

Akdeniz İhracatçı Birlikleri Genel Sekreterliği'nin yayınladığı Ocak-Aralık 2016 "Yaş Meyve ve Sebze Sektörü Türkiye Geneli Değerlendirme Raporu”na göre limon meyvesinin ihracat verileri şöyledir:

Tablo 2. Limon İhracatı Yapılan İlk 5 Ülke

\begin{tabular}{|l|l|l|l|l|}
\hline \multirow{2}{*}{ Ülkeler } & \multicolumn{2}{|l|}{$\begin{array}{l}\text { Ocak-Aralık } \\
2016\end{array}$} & $\begin{array}{l}\text { Ocak-Aralık } \\
\text { 2017 }\end{array}$ \\
\cline { 2 - 5 } & $\begin{array}{l}\text { Miktar } \\
\text { (bin } \\
\text { ton) }\end{array}$ & $\begin{array}{l}\text { Değer } \\
\text { (M\$) }\end{array}$ & $\begin{array}{l}\text { Miktar } \\
\text { (bin } \\
\text { ton) }\end{array}$ & $\begin{array}{l}\text { Değer } \\
\text { (M\$) }\end{array}$ \\
\hline Rusya & 106,5 & 77,03 & 119,5 & 82,8 \\
\hline Irak & 74,8 & 37,66 & 84,7 & 33,1 \\
\hline S. Arabistan & 57,3 & 34,21 & 63,0 & 32,5 \\
\hline Romanya & 26,6 & 25,44 & 27,9 & 22,9 \\
\hline Ukrayna & 30,3 & 16,45 & 30,4 & 14,9 \\
\hline Toplam & 450,3 & 305,9 & 475,1 & 294,7 \\
\hline
\end{tabular}

Yine aynı rapora göre, Türkiye geneli yaş meyve ve sebzede ihracat yapılan ilk 20 madde aşağıdaki çizelgede verilmiştir. Bu çizelgeden de anlaşılacağı üzere limon meyvesi Türkiye ekonomisi için oldukça önemlidir.

Tablo 3. Türkiye Geneli Yaş Meyve Ve Sebzede İhracat Yapılan İlk 20 Madde

\begin{tabular}{|c|c|c|c|}
\hline \\
\hline & \multirow{2}{*}{ Madde } & \multicolumn{2}{|c|}{ Ocak-Aralık 2016} \\
\hline & & Miktar (Kg) & Değer $(\$)$ \\
\hline 1 & Mandarin & 650721935 & 312785145 \\
\hline 2 & Limon & 450458446 & 305900124 \\
\hline 3 & Domates & 480070755 & 238314676 \\
\hline 4 & Kiraz, Vişne & 78745640 & 182756958 \\
\hline 5 & Portakal & 387641515 & 173604688 \\
\hline 6 & Üzüm & 174116369 & 105064494 \\
\hline 7 & Nar & 179920284 & 103527784 \\
\hline 8 & Biber & 98604580 & 90941816 \\
\hline 9 & Greyfurt & 183328807 & 87943472 \\
\hline 10 & Elma & 132232866 & 36674818 \\
\hline 11 & Kabak & 60285823 & 34070840 \\
\hline 12 & İncir & 14092683 & 31761142 \\
\hline 13 & $\begin{array}{l}\text { Hıyar, } \\
\text { Kornişon }\end{array}$ & 48090935 & 28334334 \\
\hline 14 & Çay & 6533820 & 28248123 \\
\hline 15 & Şeftali & 49625752 & 25511927 \\
\hline 16 & Kestane & 8263114 & 25046141 \\
\hline 17 & Kayıs1 & 35113753 & 24041180 \\
\hline 18 & Patates & 173825387 & 19776154 \\
\hline 19 & Erik & 38948692 & 13915459 \\
\hline 20 & Patlican & 25108324 & 12432443 \\
\hline \multicolumn{2}{|c|}{ Toplam YMS } & 3569540012 & 1978209380 \\
\hline
\end{tabular}

Endüstriyel kurutma işlemleri yüksek enerji tüketimi gerektiren süreçleri içerdiğinden, kurutma süresinin kısaltılmasına yönelik yapılan çalışmalar enerji tasarrufu sağlanması açısından oldukça önemlidir. Yapılan bu deney çalışmasında limon meyvesi taze hava girişli ve kapalı çevrim kurutma sistemlerinde aynı şartlarda kurutulmuş ve iki sistemin kurutma süresi üzerindeki belirgin etkileri ortaya konulmuştur.

$\mathrm{Bu}$ çalışmada deney düzeneği olarak iki ayrı 1sı pompalı infrared kurutucu tasarlanarak dilimlenmiş limon meyvesinin kurutulması analiz edilmiş ve taze hava girişinin kuruma kinetiği üzerindeki etkisi belirlenmeye çalışılmıştır.

Aktaş ve diğerleri tarafından yapılan çalışmada kızılötesi ışınımlı bir kurutucuda ayva dilimleri 3,89g $\mathrm{su} / \mathrm{g}$ kuru madde miktarından 0,16 g su / g kuru madde miktarına kadar kurutulmuştur. Aktaş bu 
çalışmasında farklı hız ve sıcaklıklarda deneyler yaparak dilimlenmiş ayvanın kuruma kinetiğini hesaplamıştır. Ayrıca Aktaş çalışmasında her bir deney için kızılötesi 1şınımlı kurutucunun da analizini yapmıştır. [1]

Meltem Onin çeşitli meyve ve sebzelerin kızılötesi 1şınımlı kurutucuda kurutulmasının deneysel ve teorik incelemesini yaptığı çalışmasında infrared 1sitma gücünün ve ön işlemlerin kuruma karakteristikleri ve kuru ürünlerin kalite parametreleri üzerindeki etkilerini incelemiştir. Onin deneyleri 300, 400 ve $500 \mathrm{~W}$ infrared kurutma güçlerinde yapmış ve kuruma hızı ve etkin difüzivetinin infrared gücünün artması ile arttığını tespit etmiştir. [2]

Nurel Arslan konveksiyonel yöntemle kurutulan mantının infrared kurutma yöntemiyle piyasada kurutulabilirliğinin incelenmesi amacıyla farklı infrared güçlerinde deneyler yapmış ve sonuçları geleneksel firında kurutma yöntemi ile karşılaştırmıştır. Deneyler sonucunda en kısa kurutma süresi $1000 \mathrm{~W}$ infrared gücü ile yapılan deneyde gerçekleşirken en fazla enerji tüketimi 500 $\mathrm{W}$ gücünde, en düşük enerji tüketimi $400 \mathrm{~W}$ gücünde gerçekleşmiştir. [3]

Darvishi, Khoshtaghaza ve Minaei mikrodalgakonvektif 1sitmanın limon dilimlerinin kurutma karakteristiklerine ve kuruma sonrası renk değişimlerine etkisini incelemişlerdir. 180, 360, 540 ve $720 \mathrm{~W}$ ve $22^{\circ} \mathrm{C}$ 'de, $1 \mathrm{~m} / \mathrm{s}$ hava hizında deneyler yapan ekip etkin nem yayılım katsayısını $1,87.10^{-8}$ $\mathrm{m}^{2} / \mathrm{s}$ ve $3,95.10^{-8} \mathrm{~m}^{2} / \mathrm{s}$ arasinda, aktivasyon enerjisini ise $10,91 \mathrm{~W} / \mathrm{s}$ olarak bulmuştur. Deneylerin sonucunda elde edilen kurutma verilerini literatürdeki mevcut matematiksel metotlarla çözümlemişler ve kurutma karakteristikleri ve renk değişimi bakımından en uygun yolu belirlemişlerdir. [4]

Chen, Hernandez ve Huang kapalı çevrim günes enerjili kurutucuda limon dilimlerinin kurutulmasını analiz etmişler ve deneyleri için yüksek geçirgen camdan kabineti olan bir fotovoltaik sistem geliştirmişlerdir. $60{ }^{\circ} \mathrm{C}$ sicak hava ile limon dilimlerini kurutmuşlardır. Deney sonuçları kapalı çevrim sistemde kurutmanın kurutma parametreleri açısından daha verimli olduğunu göstermiştir. [5]

Kesbi, Sadeghi ve Mireii tarafindan yapılan çalışmada limon dilimlerinin mikrodalga-konvektif kurutucuda kurutulmasının modellemesi ve kalite değerlendirmesi yapılmıştır. Limon dilimlerinin konvektif kurutucuda $\left(50,55\right.$ ve $60^{\circ} \mathrm{C}$ giriş hava sicaklıklarında), mikrodalga firında $\left(0,97 \mathrm{~W} \mathrm{~g}^{-1}\right.$ spesifik güç) ve kombine mikrodalga-konvektif kurutucuda $\left(0,97 \mathrm{~W} \mathrm{~g}^{-1}\right.$ ve $2,04 \mathrm{~W} \mathrm{~g}^{-1}$ spesifik güç ve 50,55 ve $60^{\circ} \mathrm{C}$ giriş hava sıcaklıklarıyla desteklenmiş) kuruma davranışları incelenmiştir. Yapılan deneyler sonucunda mikrodalga-konvektif kurutucuda kurutulan limonların yüksek kuruma hızına ek olarak ürünün kalite parametreleri de diğer kurutma metodlarına göre yüksek bulunmuştur. [6]

Aktaş ve Kara tarafından yapılan çalışmada Güneş Enerjisi ve Isı Pompalı Kurutucuda Dilimlenmiş Kivi kurutulmuştur. Çalışmada kurutucu tasarlanmış, imal edilmiş ve kivi meyvesi kurutularak deneysel olarak incelenmiştir. $5 \mathrm{~mm}$ kalınlığında dilimlenen kiviler 6 $\mathrm{g} / \mathrm{su}$ kuru madde başlangıç nem miktarından $35^{\circ} \mathrm{C}$ sicaklıkta $0,53 \mathrm{~g} \mathrm{su} / \mathrm{g}$ kuru madde, $40{ }^{\circ} \mathrm{C}$ sicaklikta $0,25 \mathrm{~g} \mathrm{su} / \mathrm{g}$ kuru madde, $45^{\circ} \mathrm{C}$ sicaklikta $0,14 \mathrm{~g} \mathrm{su} / \mathrm{g}$ kuru madde ve 50 oC sicaklikta $0,15 \mathrm{~g}$ su/g kuru madde nem miktarına kadar kurutulmuştur. Kiviler, $35{ }^{\circ} \mathrm{C}, 40{ }^{\circ} \mathrm{C}, 45{ }^{\circ} \mathrm{C}$ ve $50{ }^{\circ} \mathrm{C}$ kurutma havas 1 sıcaklığında ve değişken hava hızlarında $(0,1-1,0$ $\mathrm{m} / \mathrm{s}$ ) ve sirasiyla 8,5 saat, 7,5 saat, 7,5 saat ve 6,5 saatte kurutulmuştur. Isı pompası performans katsayısı (COPhp,h) ve tüm sistemin 1s1 pompası performans katsayısı (COPts) bütün deneyler için ortalama olarak sirasiyla 2,90 ve 2,27 olarak hesaplanmıştır. Bununla beraber yapılan tüm deneyler için ortalama dalgalı kanatçıklı havalı güneş kolektörünün verimi \% 56,7 olarak hesaplanmıştır. $\mathrm{Bu}$ deneysel çalışma ile, kivi kurutulması için uygun kurutma havası sıcaklık değeri $50 \quad{ }^{\circ} \mathrm{C}$ olarak belirlenmiştir. [7]

Tokdemir, 1s1 pompası destekli kurutucuda toz elma ve elma cipsi üretiminin performans analizini yapmıştır. $40 \quad{ }^{\circ} \mathrm{C}$ kurutma havası sıcaklığında gerçekleştirdiği deneylerinde kurutma havası hızını 1 $\mathrm{m} / \mathrm{s}$ olarak belirlemiştir. Yapılan deneysel çalışma sonucunda tüm sistem için performans katsayısı değerleri, rendelenmiş elma için 3,02 olarak belirlenirken, elma dilimleri için 2,82 olarak hesaplanmıştır. Rendelenmiş elmaların kurutulması 4 saat sürmüş ve kurutma işlemi sonunda nem içeriği $5,06 \mathrm{~g}_{\mathrm{su}} / \mathrm{g}_{\text {katı madde }}$ nem miktarından $0.17 \mathrm{~g}_{\mathrm{su}} / \mathrm{g}_{\text {katı madde }}$ nem miktarına düşmüştür. Elma dilimleri ise 5,06 $\mathrm{g}_{\text {su }} / \mathrm{g}_{\text {katı madde }}$ nem miktarından $0.17 \mathrm{~g}_{\text {su }} / \mathrm{g}_{\text {katı madde }}$ nem miktarına 9 saat süren kurutma işlemi sonunda ulaşmıştır. [8]

Gürlek ve diğerleri ısı pompalı kurutucuda elma meyvesinin kurutulmasını analiz etmişlerdir. Çalışmalarında 1sı pompası destekli kurutucuların çalışma prensiplerinden ve bu kurutucuların performans kıstaslarından bahsederken, $50^{\circ}$ ' de kuruttukları elma dilimlerini incelemişlerdir. Çalışma neticesinde tercih ettikleri sistemin enerji tüketiminin diğer kurutma sistemlerine göre daha düşük olduğunu buna karşın elde edilen kurutulmuş 
elmaların diğer sistemlerde kurutulan elmalara göre daha kalitesiz olduğunu belirtmişlerdir [9].

\section{MATERYAL VE METOT (MATERIAL AND METHOD)}

\subsection{Metot (Method)}

Kurutma sistemi tasarlanırken kurutulacak ürünün ve kurutma sisteminin özellikleri göz önünde bulundurulmuş ve sistem buna göre tasarlanmıştır.

Kurutulan limonların nem kontrolünün yapılabilmesi için deneye başlamadan nem kontrolünün yapılması gerekmektedir. Bunun için işlemden önce limonlar $100 \pm 2{ }^{\circ} \mathrm{C}$ sabit sicaklıktaki bir firında kurutulmuş ve bu kurutma işlemi sırasında periyodik aralıklarla ağırlıkları ölçülmüştür. İki ölçüm arasındaki ağırlığın \%1'den az olduğu durumda limonlar kuru kabul edilmiştir.

\subsubsection{Nem içeriği (Moisture content)} 0];

Limon dilimlerinin kuru esasa göre nem miktar

$M C_{d b}=\frac{M_{i}-M_{d}}{M_{d}}$

Ve limon dilimlerinin yaş esasa göre nem miktarı [10];

$M C_{i b}=\frac{M_{i}-M_{d}}{M_{i}}$

\subsubsection{Nem oranı (Moisture ratio)}

$M R=\frac{M-M_{e}}{M_{o}-M_{e}}$

Bu denklemde $\mathrm{M}$ nem içeriğini, Mo başlangıçtaki nem içeriğini, $\mathrm{Me}$ ise denge durumundaki nem içeriğini tanımlamaktadır [10].

Taze üründeki yüksek nemden dolayı eşitlik şu şekilde yazılabilir [10];

$M R=\frac{M}{M_{o}}$

\subsubsection{Kuruma hızı (Drying rate)}

Kuruma hızı aşağıdaki denklem ile hesaplanmaktadır [10].

$D R=\frac{\mathrm{MC}_{\mathrm{t}-\mathrm{dt}}-\mathrm{MC}_{\mathrm{t}}}{\mathrm{dt}}$

\subsubsection{Isı pompalı kurutucu (Heat pump dryer)}

Analizi yapılan bu kurutma sisteminde sürekli akışlı açık sistem için enerjinin korunumu en genel halde;
$\dot{Q}-\dot{W}=\Sigma \dot{\mathrm{m}}_{i a} \cdot\left(h_{o a}-h_{i a}+\frac{v_{o a^{2}-v_{i a}{ }^{2}}}{2}\right)$

eşitliği ile ifade edilir [12]

Kurutma odasında kızıl ötesi 1şınım ile yapılan kurutma işlemi esnasında, 1sı değişimi psikrometrik diyagram yardımıyla;

$\dot{Q}=\dot{\mathrm{m}}_{i a} \cdot\left(h_{o a}-h_{i a}\right)$

eşitliği ile hesaplanır [12].

Is1 geri kazanım cihazıyla atık havadan kazanılan enerji [10].;

$\dot{Q}_{K}=\dot{\mathrm{m}}_{i a} \cdot \dot{c}_{p i a} \cdot\left(T_{i a}-T_{o a}\right)$

$\dot{m}_{i a}=\rho_{i a} \cdot \dot{V}_{i}$

Bir 1S1 pompas1 setinde 1sitma tesir katsay1s1 $\left(C O P_{h p}\right)$ aşağıdaki eşitlik yardımıyla hesaplanmaktadır [10].

$C O P_{h p}=\frac{\dot{Q}_{K}}{\dot{W}_{C}}$

Tüm deney düzeneği için COP yani 1sıtma tesir katsayısının $\left(C O P_{w s}\right)$ bulunmasında aşağıdaki eşitlik kullanılmaktadır [10];

$C O P_{w s}=\frac{\dot{Q}_{K}}{\dot{W}_{C}+\dot{W}_{f}}$

$1 \mathrm{~kg}$ nem almak için kullanılması gereken enerji "özgül nem çekme oranı (SMER)" olarak tanımlanır ve aşağıdaki eşitlik ile hesaplanır [10].;

$S M E R=\frac{\dot{m}_{d}}{\dot{W}_{C}}$

Tüm deney düzeneği için $\left(S M E R_{W S}\right)$ ise [10].;

$S M E R_{W S}=\frac{\dot{m}_{d}}{\dot{W}_{C}+\dot{W}_{f}}$

\subsubsection{Belirsizlik analizi (Uncertainty analysis)}

Deneysel çalışmalarda oluşabilecek hataların analizi için belirsiz analizi yöntemi kullanılır. Oluşan hatalar göz önüne alınarak toplam hata;

$W_{R}=\left[\left(\frac{\partial R}{\partial x_{1}} W_{1}\right)^{2}+\left(\frac{\partial R}{\partial x_{2}} W_{2}\right)^{2}+\ldots+\left(\frac{\partial R}{\partial x_{n}} W_{n}\right)^{2}\right]^{1 / 2}$

eşitliği ile hesaplanır [7]. Bu eşitlikte R ölçülmesi gereken büyüklük, $x_{1}, x_{2}, x_{3}, \ldots, x_{n}$ ise bu büyüklüğe etli eden $n$ tane bağımsız değişkenlerdir. 


\subsection{Materyal (Material)}

Deneyler Gazi Üniversitesi Teknoloji Fakültesi Enerji Sistemleri Bölümü Laboratuvarında gerçekleştirilmiştir. Yapılan deneylerde aynı cins ve boyutta limonlar, $5 \mathrm{~mm}$ kalınlığında eşit dilimler haline getirilerek kullanılmıştır.

Kurutma analizine başlamadan önce etüv yöntemi ile limonların nem içeriğin belirlenmiştir. Limon dilimleri $\quad 100^{\circ} \mathrm{C} \quad$ sicaklikta kurutularak ağırlıklarındaki değişim her 20 dakikada bir ölçülmüştür. Son iki ölçüm sonucu arasındaki fark $\% 1$ oluncaya kadar kurutma işlemine devam edilmiştir. Bu analiz 3 kere tekrar edilmiştir.

Limonların tartılmasında $\pm 0,01 \mathrm{~g}$ hassasiyete sahip Mettler Toledo markasının dijital tartısı kullanılmıştır. Deney öncesi yapılan bu analizle limonların nem içeriği yaş bazda $0,8698 \mathrm{gsu} / \mathrm{g}$ yaş ağırlık olarak, kuru bazda 6,6804 gsu/g kuru ağırlık olarak hesaplanmıştır.

Deney öncesi limonlar oda sıcaklığına gelmesi için bekletilmiş, ardından $5 \mathrm{~mm}$ kalınığında halkalar halinde dilimlenmiştir. Limon dilimleri deney düzeneğindeki 1zgara tepsiye yatay olarak dizilmiştir. Deney öncesi sistem kararlı hale gelene kadar 45 dakika çalıştırılmıştır.

Kızıl ötesi 1şınım ile limon dilimlerinin kurutulması için kurutma sistemi analiz edilmiştir. Taze hava girişinin kurutma üzerindeki etkilerini gözlemleyebilmek için hem kapalı çevrim hem de taze hava girişli olmak üzere iki deney düzeneği ayrı ayrı tasarlanmış ve imal edilmiştir.

Tasarlanan her iki sistemde de 1s1 pompası ilavesi ise sistem verimliliği artırılmıştır.

Kurutucu düzenekte kullanılan PLC kontrol sistemi ile deney sirasinda elde edilen verilerin bilgisayara aktarılması ve kurutma havasının bağıl neminin, sıcaklığının, hızının kontrolü ve aynı zamanda kurutulan limon dilimlerinin ağırlık değişimlerinin gözlemlenmesi mümkün olmuştur.

Kullanılan kurutma sistemi 370W'lık kompresör, R-134a soğutucu akışkan, yoğuşturucu, buharlaştırıcı, fan (160 W \& $990 \mathrm{~m} 3 / \mathrm{h})$, pompa (370 W, 2,4 m3/h), su deposu (40 litre), frekans invertörü, anemometre, , filtre, k1lcal boru, $20 \mathrm{~kg}$ ölçme kapasitesine sahip ağırlık ölçer, elektronik elektrik sayac1, kurutma odası ve PLC kontrol cihazından (sıcaklık ve ağırlık ölçümü, $1 \mathrm{MB}$ uygulama hafizası artı $512 \mathrm{~K}$ font ve $3 \mathrm{MB}$ resim hafizası, LCD LED dokunmatik ekran, operatör paneli) oluşmaktadır. Kullanılan her iki kurutucu sistem de bu ekipmanları içermektedir.

Şekil 1'de ilk deneyin yapıldı̆̆ı kapalı devre kurutma sistemi, Şekil 2'de ise ikinci deneyin yapıldığı ve sisteme taze hava girişinin sağlandığ1 kurutma sistemi ve bu sistemlerdeki değerlerin ölçüm noktaları gösterilmiştir.

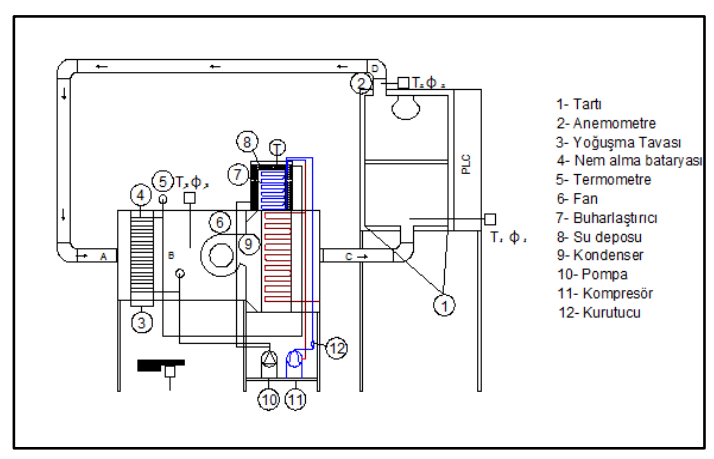

Şekil 1. Kapalı devre kurutma sistemi (Closed loop drying unit)

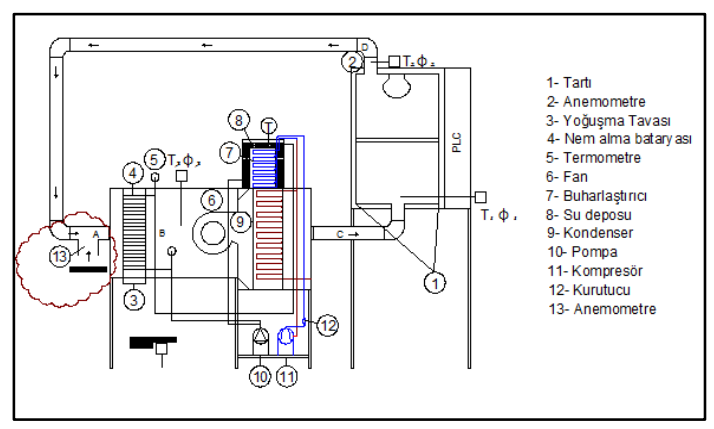

Şekil 2. Taze hava girişli kurutma sistemi (Fresh airinlet drying unit)

Tablo 4. Ölçüm Cihazının Teknik Özellikleri (Technical Properties of Measurement Equipment)

\begin{tabular}{|c|c|c|c|}
\hline $\begin{array}{l}\text { Sistem } \\
\text { elemanı }\end{array}$ & Teknik özellikler & Doğruluk & Belirsizlik \\
\hline $\begin{array}{l}\text { Hava akış1 } \\
\text { ölcüm cihazı }\end{array}$ & $\mathrm{H} 1 \mathrm{z} 0-20 \mathrm{~m} / \mathrm{s}$ & $\pm 0,01 \mathrm{~m} / \mathrm{s}$ & $\pm 0,031 \mathrm{~m} / \mathrm{s}$ \\
\hline Isıl çift & $\begin{array}{l}\text { Skala }-200^{\circ} \mathrm{C} \\
\sim+850^{\circ} \mathrm{C} 0-70^{\circ} \mathrm{C}, \\
\text { besleme } 24 \mathrm{~V}-\mathrm{DC} \text {, } \\
\text { çıkış } 4-20 \mathrm{~mA}\end{array}$ & $\pm 0,4^{\circ} \mathrm{C}$ & $\pm 0,648^{\circ} \mathrm{C}$ \\
\hline Yük Hücresi & $\begin{array}{l}2,0 \mathrm{mV} / \mathrm{V}, 5-12 \mathrm{~V},- \\
35+60^{\circ} \mathrm{C}\end{array}$ & $\pm 0,2 \%$ & $\pm 0,057 \%$ \\
\hline $\begin{array}{l}\text { Sicaklık ve } \\
\text { bağıl nem } \\
\text { ölçüm cihazı }\end{array}$ & $\begin{array}{l}0-100 \% \text { bağ } 11 \text { nem, } \\
-40 \text { 'tan }+70^{\circ} \mathrm{C} \text { 'ye }\end{array}$ & $\begin{array}{l} \pm 2 \% \mathrm{RH} \\
\pm 1^{\circ} \mathrm{C}\end{array}$ & $\begin{array}{l} \pm 2,236 \% \\
\mathrm{RH} \\
\pm 1,118^{\circ} \mathrm{C}\end{array}$ \\
\hline $\begin{array}{l}\text { Elektrik } \\
\text { ölçer }\end{array}$ & $220 \mathrm{~V}$ & $\pm 1 \%$ & $\pm 1,41 \%$ \\
\hline Dijital tartı & $\begin{array}{l}\text { Maksimum ölçüm } \\
\text { kapasitesi, } 6100 \mathrm{~g}\end{array}$ & $\pm 0,01 \mathrm{~g}$ & $\pm 0,052 \mathrm{~g}$ \\
\hline
\end{tabular}


Kurutma sisteminde enerji kaynağ 1 olarak 1S1 pompasının yoğuşturucu kısmı, depodaki suyun düşük sıcaklıkta saklanmasını sağlamak için ise 1s1 pompasının buharlaştırıcı kısmı kullanılmaktadır.

Sistemde ilk deneyde kapalı devre, ikinci deneyde taze hava ile karışık olarak dolaşan kurutma havası, üründe mevcut olan nemi almakta ve böylece kurutma havasının nemi artmaktadır. Buharlaştırıcıda sağlanan soğuk su, pompa ile 1s1 değiştiricisine gönderilir ve soğuk yüzeyde kurutma havasının nemini yoğuşturur. Kurutma sisteminde PLC kontrol cihazında ayarlanan sıcaklık, bağıl nem değeri sıcaklık-bağıl nem sensörü ile ve hava hızı anemometre ile ölçülüp set değerlerine göre kontrol edilmektedir. Eğer PLC'de girilen değer 1sıl çift ile ölçülen sicaklıktan büyük ise, kompresör devreye girer ve sıcaklık artışı sağlanır.

Buharlaştırıcı tarafından soğutulan suyun istenildiğinde pompa yardımı ile dolaşımı sağlanıp,sistemde kurutma havasının bağıl neminin kontrolü sağlanmaktadır. Deney boyunca kurutma kabinindeki ağırlık ölçer ile limonların ağırlık değişimi izlenmiş ve her 10 dakikada bir not edilmiştir. Deney esnasında ortam havası sıcaklığı ortalama $20{ }^{\circ} \mathrm{C}$ ve ortam havası bağıl nemi ortalama $\% 50$ 'dir.

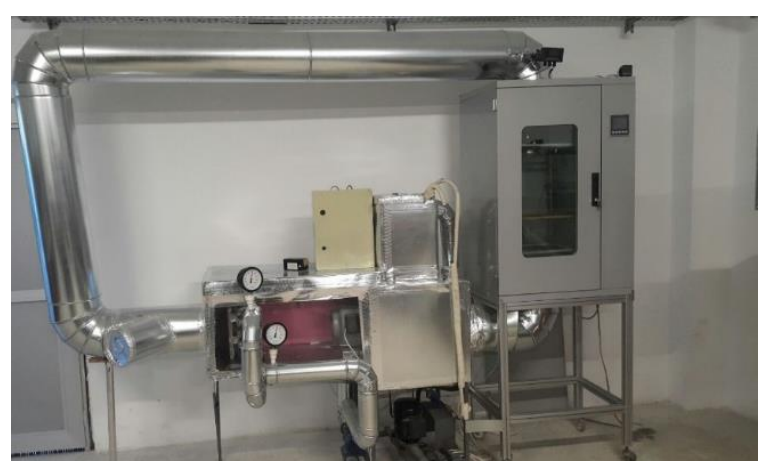

Şekil 3. Kurutma Ünitesi ( The Drying Unit)

\section{DENEY VE ANALIZ SONUÇLARI (EXPERIMENT AND ANALYSIS RESULTS)}

Kurutma deneyine başlamadan önce limonların nem içeriği Eş. 1. kullanılarak 6,6804 g su/g kuru madde olarak hesaplanmıştır. Deneyler $60{ }^{\circ} \mathrm{C}$ sabit sıcaklıkta ve $1 \mathrm{~m} / \mathrm{s}$ hava hızında gerçekleşmiştir.

Hazırlanan her iki sistem için de deneyler tamamlandıktan sonra elde edilen veriler ile nem içeriğinin zamana göre değişimi hesaplanmıştır.

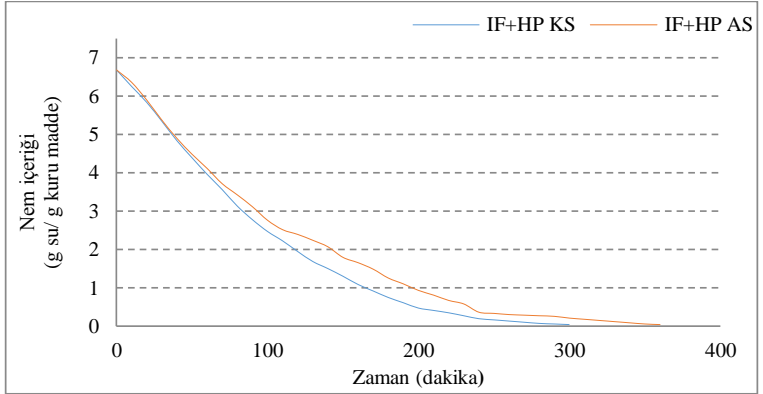

Şekil 4. Zamana göre nem içeriğinin değişimi (Change of moisture content according to time)

Şekil 4'de verilen grafikten de görüldüğü üzere, taze hava girişi olan kurutma düzeneğinde kurutma işlemi 6 saat sürerken, kapalı sistemde kurutma işlemi 5 saatte tamamlanmıştır.

Her iki sistem için ayrı olarak MR değerleri hesaplanmış ve Şekil 5'de verilmiştir.

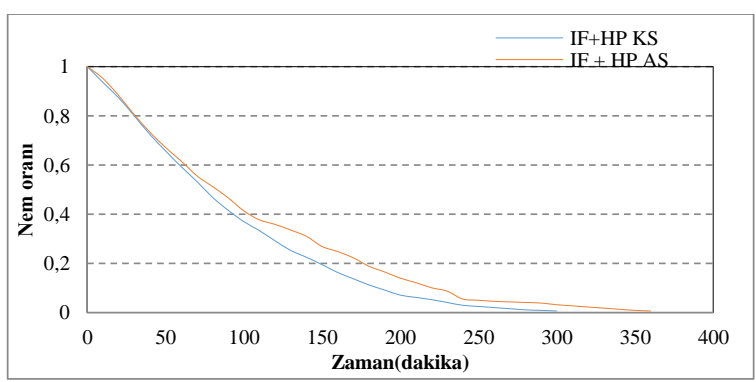

Şekil 5. Zamana göre nem oranının değişimi (Change of moisture ratio according to time)

Yapılan deneylerde nem oranı 1'den başlayarak 0,06'ya kadar düşmüştür.

Her 10 dakikada bir yapılan ağıllık ölçümlerine ilave olarak yine aynı periyotta diğer tüm veriler not edilmiştir.

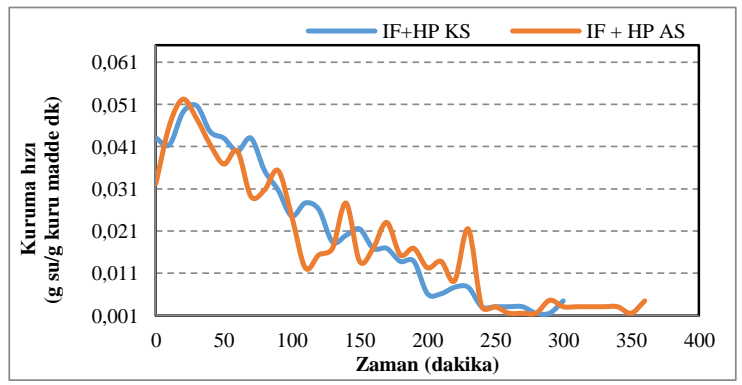

Şekil 6. Zamana göre kurutma hızının değişimi (Change of drying rate according to time)

Deneyler aynı şartlarda gerçekleştirilmiş ve her iki sistemde de aynı şartlarda ve aynı miktarda limonun kurutulması için geçen süre ölçülmüştür. Kurutma işlemi kapalı çevrim kurutma sisteminde 
taze hava girişli kurutma sistemine göre daha kısa sürede tamamlanmıştır.

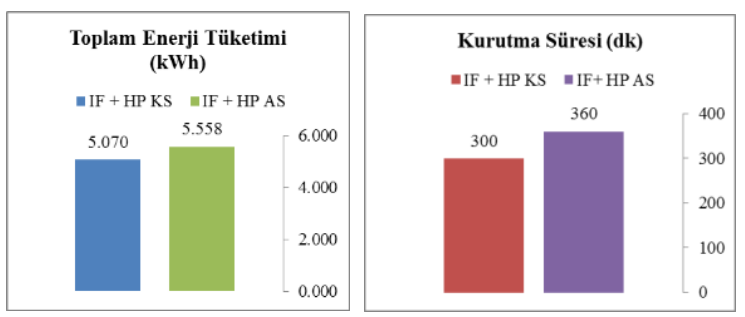

Şekil 7. Enerji tüketimi ve kurutma süresi (Energy consumption and drying time)

İki deneydeki enerji tüketimi sistemdeki sayaçtan okunmuş ve Şekil 8'deki grafikte gösterilmiştir.

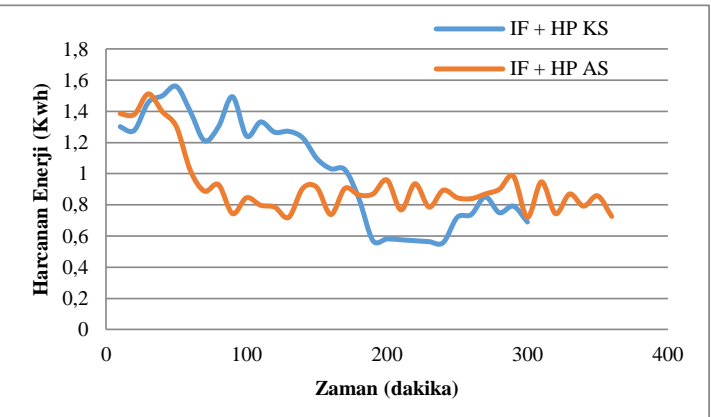

Şekil 8. Zamana göre harcanan enerji değişimi (Energy exchange by time)

Tüketilen toplam enerjinin büyük kısmı her iki sistemde de infrared lambada kullanılmıştır. Kapalı sistemde infrared lambanın kullandığı enerji açık sisteme göre yaklaşık $\% 6$ oranında düşerken, kompresörde tüketilen enerji oranı artmıştır.

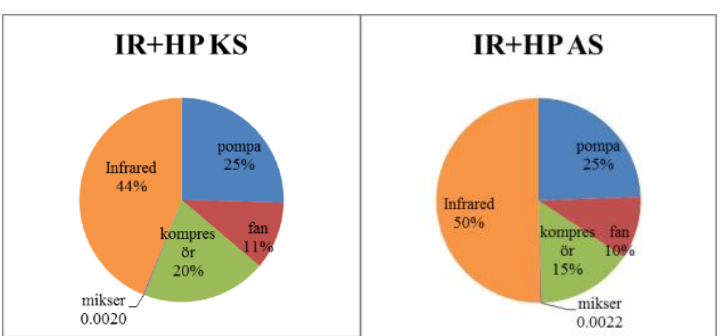

Şekil 9. Toplam enerji tüketiminin dağılımı (Evaluation of total energy consumption ratios)

İki deneyde de 1sitma tesir katsayısı $\left(C O P_{w s}\right)$ hesaplanmış ve zamana göre değişimi aşağıdaki grafikte gösterilmiştir.

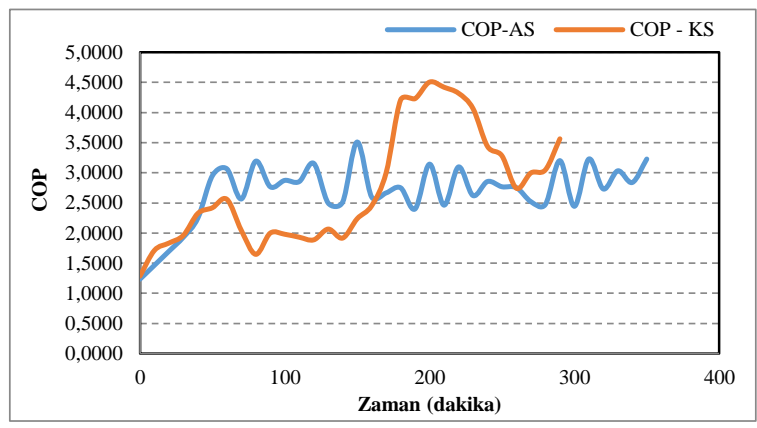

Şekil 10. Zamana göre COPws'nin değişimi (Change of COPws by time)

Hesaplanan ortalama COPws değeri taze hava girişli sistem için 2,67, kapalı çevrim sistem için 2,74 olarak bulunmuştur.

Her iki sistemin kurutma verimi aşağıdaki grafikte karşılaştırılmıştır.

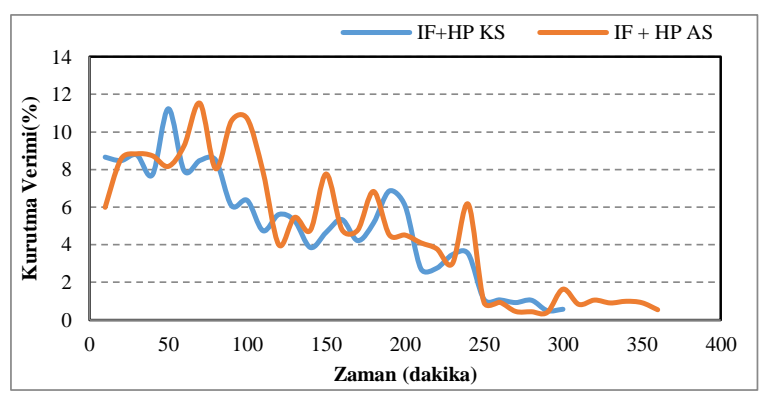

Şekil 11. Kurutma verimi (Efficiency of drying)

\section{SONUÇ (CONCLUSION)}

Yapılan bu deneyler sonucu aşağıdaki sonuçlara ulaşılmıştır.

Limon dilimlerinin $6,6804 \mathrm{~g}$ su/g kuru madde başlangıç nem miktarından $0,045 \mathrm{~g} \mathrm{su} / \mathrm{g}$ kuru madde nem miktarına düşmesi taze hava girişli sistemde 360 dakika, kapalı çevrim sistemde 300 dakika sürmüştür.

Yapılan hesaplama sonucunda limon dilimlerinin kapalı çevrim sistemde kurutulmasındaki ortalama COPws 2,74 olarak, taze hava girişli sistemde kurutulmasindaki COPws ise 2,67 olarak bulunmuştur. $\mathrm{Bu}$ hesaplamalar sonucunda kapalı çevrim sistemde kurutmanın taze hava girişli sisteme göre daha verimli olduğu görülmüştür.

Taze hava girişli sistemde limon dilimlerinin kurutulması işlemi, kapalı çevrim olarak çalışan sisteme göre 60 dakika daha uzun sürmüştür. Bunun nedeni sisteme alınan taze havanın kurutma havasının sıcaklığını düşürmesidir. 
Enerji tüketimi ve kurutma verimi açısından incelendiğinde kapalı çevrim kurutma sisteminin daha avantajlı olduğu görülmüştür.

Kurutulmuş limon dilimlerinin saklanması, taşınması ve kullanımı taze limona göre çok daha kolaydır.

Isı pompalı kurutucu, infrared ile desteklendiğinde kurutma süresinin ve enerji tüketiminin azaldığ 1 belirlenmiştir. Yapılan bu çalışma literatürdeki benzer çalışmalar ile karşılaştırıldığında, taze hava girişinin olmadı $\breve{g}$ sistemlerde kurutma havasının sıcaklığı ve nemi daha iyi korunduğu için daha kısa sürede ve daha az enerji tüketerek kurutma işleminin gerçekleştiği görülmüştür.

Yapılan bu çalışma neticesinde limon meyvesinin kurutulmasına dair aşağıdaki önerilerde bulunulabilir.

Kurutucu düzenekte limon haricinde başka gida maddelerinin de kurutulması mümkündür.

Kurutucu düzeneğe güneş enerjisi desteği ilave edilebilir. Bu sayede enerji tüketimi azaltılabilir.

Kurutulan limon dilimlerinin gözle analizi yapıldığında limon dilimlerinde kurutma işlemi sonrası kararma olduğu gözlenmiştir. Bu durumun ürünün pazarlanmasında dezavantaj yaratabileceği öngörülmektedir. Limonların kararmasını önlemek için kurutma işleminden önce bir limon dilimlerine bir ön işlem yapılabilir.

\section{SIMGELER (SYMBOLS)}

c: Havanın özgül 1sısı, $\mathrm{kJ} / \mathrm{kg}^{\circ} \mathrm{C}$

$C O P_{h p}$ : Isı pompasının performans katsayısı

$C O P_{w s}$ : Bütün sistemin performans katsayıs1

ÇBN: Çevre havası bağıl nemi

$D R$ : Kurutma hızı, $\mathrm{g}$ su/ $\mathrm{g}$ kuru madde dakika

$M C_{d b}$ : Nem içerĭği, $\mathrm{g} \mathrm{su} / \mathrm{g}$ kuru madde

$M_{i}$ : Başlangıçtaki yaş ağırlık, $\mathrm{g}$

$\dot{m}_{d}$ : Buharlaştırılan su miktarı, $\mathrm{kg} / \mathrm{h}$

$M_{d}:$ Kuru ağırlık, g

$M C_{t}: \mathrm{t}$ anına göre nem içeriği, $\mathrm{g} \mathrm{su} / \mathrm{g}$ kuru madde

$M C_{t+d t}: \mathrm{t}+\mathrm{dt}$ anına göre nem içeriği, $\mathrm{g}$ su/g kuru madde

$M R:$ Nem oranı

$M$ : Ürünün herhangi bir seviyede ve zamandaki nem içeriği, g su/g kuru madde

$M_{e}$ : Denge nem içeriği, g su/g kuru madde

$M_{o}$ : Başlangıçtaki nem içeriği, $\mathrm{g} \mathrm{su} / \mathrm{g}$ kuru madde

$\dot{m}_{i a}$ : Havanın kütlesel debisi, $\mathrm{kg} / \mathrm{s}$

$\rho:$ Havanın yoğunluğu, $\mathrm{kg} / \mathrm{m}^{3}$

$S M E R_{h p}$ : Isı pompasının özgül nem çekme oranı, $\mathrm{kg} / \mathrm{kWh}$

$S M E R_{w s}:$ Tüm sistemin özgül nem çekme oran1, $\mathrm{kg} / \mathrm{kWh}$
$T_{i a}$ : Giriş havası sıcaklığı, ${ }^{\circ} \mathrm{C}$

$T_{o a}:$ Çıkış havası sıcaklığı, ${ }^{\circ} \mathrm{C}$

$\dot{V}:$ Hava debisi, $\mathrm{m}^{3} / \mathrm{h}$

$\dot{Q}_{K}$ : Yoğuşturucudan kurutma havasına verilen 1S1 gücü, $\mathrm{kW}$

$\dot{W}_{c}$ : Kompresör gücü, $\mathrm{kW}$

$\dot{W}_{f}:$ Fan gücü, $\mathrm{kW}$

\section{KAYNAKLAR (REFERENCES)}

[1] M. Aktaş, M. İlbaş, A. Yalçın ve M. Şahin. "Kızılötesi Işınımlı Bir Kurutucuda Kuruma Davranışlarının Deneysel İncelenmesi" Gazi Üniv. Müh. Mim. Fak. Dergisi, vol. 28, no. 4, pp. 767-775, 2013.

[2] M. Onin, "Bazı Meyve ve Sebzelerin İnfrared Kurutucuda Kurutulmasının Deneysel ve Teorik İncelenmesi," Yüksek Lisans Tezi, İnönü Üniversitesi Fen Bilimleri Enstitüsü, Malatya, 2012.

[3] N. Arslan. "İnfrared Kurutma Yönteminin Kurutulmuş Manti Kalitesi Üzerine Etkisi”, Yüksek Lisans Tezi, Çanakkale On sekiz Mart Üniversitesi Fen Bilimleri Enstitüsü, Çanakkale, 2012.

[4] H. Darvishi, M. Khoshtaghaza, S. Minaei, "Drying kinetics and colour change of lemon slices", International Agrophys, vol. 28, no. 1, pp. 1-6, 2014.

[5] H. Chen, C. E. Hernandez and T. Huang, "A study of the drying effect on lemon slices using a closed-type solar dryer", Solar Energy, vol. 78, no. 1, pp. 97-103, 2005.

[6] M. Sadeghi, O. Mirzabeigi Kesbi and S.A. Mireei, "Mass transfer characteristics during convective, microwave and combined microwaveconvective drying of lemon slices", Journal of the Science of Food and Agriculture, vol. 93, no. 3, pp. 471-8, 2013.

[7] M. Aktaş, Ç. Kara, "Güneş Enerjisi Ve Isı Pompalı Kurutucuda Dilimlenmiş Kivi Kurutulması", Gazi Üniv. Müh. Mim. Fak. Dergisi, vol. 28, no. 4, pp. 733-741, 2013.

[8] M. Tokdemir, "Is1 pompası destekli kurutucuda toz elma ve elma cipsi üretiminin performans analizi”, Yüksek Lisans Tezi, Gazi Üniversitesi Fen Bilimleri Enstitüsü, Ankara, 2018.

[9] G. Gürlek, Ö. Akdemir ve A. Güngör, "Gıda kurutulmasında 1s1 pompalı kurutucuların kullanımı ve elma kurutmada uygulanması", Pamukkale 
Üniversitesi Mühendislik Bilimleri Dergisi, vol. 21, no. 9, pp. 398-403, 2015.

[10] M. Aktaş, T. Menlik, K. Boran, B. Aktekeli ve Z. Aktekeli, "Is1 pompalı bir kurutucuda portakal kabuğu kurutulması", Gazi Üniversitesi Fen Bilimleri Dergisi, vol. 2, no. 2, pp. 229-238, 2014.

[11] D. Shofinita, S. Feng and T. A. G. Langrish, "Comparing yields from the extraction of different citrus peels and spray drying of the extracts", Advanced Powder Technology, vol. 26, no. 6, pp. 1633-1638, November 2015.

[12] M. Aktaş ve E. Gönen, "Isı pompalı nem kontrollü bir kurutucuda defneyaprağ 1 kurutulması", Gazi Üniversitesi Mühendislik-Mimarlık Fakültesi Dergisi, vol. 29, no. 2, pp. 433-441, 2014.

[13] H. Günerhan, "Endüstriyel Kurutma Sistemleri", Türk Tesisat Mühendisleri Dergisi, vol. 36, no. 13, pp. 1-10, 2005.

[14] B. Erbay ve E. Küçüköner, "Gıda Endüstrisinde Kullanılan Farklı Kurutma Sistemleri”, Türkiye 10. Glda Kongresi, May 21-23, 2008, Erzurum.

[15] M. Aktaş, İ. Ceylan ve H. Doğan, "Güneş Enerjili Kurutma Firınında Elma Kurutulması”, Journal of Polytechnic, vol. 9, no. 4, pp. 289-294 2006

[16] A. S. Mujumdar, Handbook of Industrial Drying, Fourth Edition, Boca Raton, FL: CRC, 2015.

[17] S. Wannapakhe, T. Chaiwong, M. Dandee and S. Prompakdee, "Hot Air Dryer with Closed - Loop Oscillating Heat Pipe with Check Valves for Reducing Energy in Drying Process", Procedia Engineering, vol. 32, no. 1, pp. 77-82, 2012.

[18] Z. Lataoui, C. Romestant, Y. Bertin, A. Jemni and D. Petit, "Inverse thermal analysis of the drying zone of the evaporator of an axially grooved heat pipe", Experimental Thermal and Fluid Science, vol. 34, no. 5, pp. 562-574, July 2010.

[19] H. Abbasi, A. Seidavi, W. Liu and L. Asadpour, "Investigation on the effect of different levels of dried sweet orange (Citrus sinensis) pulp on performance, carcass characteristics and physiological and biochemical parameters in broiler chicken", Saudi Journal of Biological Sciences, vol. 22, no. 2, pp. 139-146, March 2015.
[20] M. Aktaş, İ. Ceylan ve H. Doğan, “Isı Pompalı Endüstriyel Findik Kurutma Firınının Modellenmesi”, Journal of Polytechnic, vol. 8, no. 4, pp. 329-336, 2005.

[21] M. Aktaş ve B. Aktekeli, "Isı Pompalı Kurutucuda Atık Isı Kullanımının Performansa Etkisi ve Deneysel Analizi”, Tartm Bilimleri Dergisi, vol. 21, no. 2, pp. 220-235, March 2015.

[22] İ. Ceylan, "Programlanabilir (PLC) Isi Pompali Kurutucunun Tasarimi, İmalati Ve Kereste Kurutma İşleminde Deneysel İncelenmesi”, Doktora Tezi ,Gazi Üniversitesi Fen Bilimleri Enstitüsü, Ankara, 2007.

[23] B. Fox, G. Bellini and L. Pellegrini, "Fermentation and Biochemical Engineering Handbook", Third Edition, Waltham, MA: William Andrew, 2014.

[24] H. Doğan, "Kurutmada Kullanılan Hava Isıtma Kollektörlerinin Deneysel Karşılaștırılmasıı", Teknoloji Dergisi, vol. 4, no. 1-2, pp. 75-82, 2001.

[25] M. Abuşka ve H. Doğan, "Endüstriyel tip 1s1 pompalı kurutucuda çekirdeksiz üzümün kurutulması", Politeknik Dergisi, vol. 13, no. 4, pp. 271-279, 2010.

[26] P. Meena, S. Rittidech and N. Poomsa-ad, "Application of closed-loop oscillating heat-pipe with check valves (CLOHP/CV) air-preheater for reduced relative-humidity in drying systems", Applied Energy, vol. 84, no. 5, pp. 553-564, 2007.

[27] M. Aktaş, S. Şevik, B. Özdemir and E. Gönen, "Performance analysis and modeling of a closed-loop heat pump dryer for bay leaves using artificial neural network", Applied Thermal Engineering, vol. 87, no. 1, pp. 714-723, August 2015. 


\section{Simge Pelin ALKAÇ}

Simge Pelin Alkaç, 1987 yılında Amasya'da doğmuştur. 2012 yılında Erciyes Üniversitesi Mühendislik Fakültesi Makine Mühendisliği bölümünden mezun olmuştur. 2019 yılında Gazi Üniversitesi Enerji Sistemleri Mühendisliği bölümünde yüksek lisans derecesini almıştır. İlgi alanları arasında endüstriyel kurutma sistemleri, enerji verimliliği, termodinamik ve 1 si transferi konuları bulunmaktadır.

\section{Kurtuluş BORAN}

Kurtuluş Boran 1956 yılında Niğde'de doğmuştur. Eskişehir Devlet Mühendislik ve Mimarlık Akademisi Makina Mühendisliği bölümünde eğitimini tamamladıktan sonra Gazi Üniversitesi Fen Bilimleri Enstitüsü Makina Eğitimi bölümünden yüksek lisans derecesini almıştır. 1993 yılında Erciyes Üniversitesi Fen Bilimleri Enstitüsü Makina Mühendisliği bölümünde doktora eğitimini tamamlamıştır. Halen Gazi Üniversitesi Teknoloji Fakültesi Enerji Sistemleri Mühendisliğinde Profesör Doktor unvanıla görevini sürdürmektedir. İlgi alanları arasında termodinamik, 1S1 transferi, akışkanlar mekaniği, soğutma uygulamaları ve 1s1 ekonomisi konuları bulunmaktadır.

\section{Mustafa AKTAŞ}

Mustafa Aktaş 2000 yılında Gazi Üniversitesi Teknik Eğitim Fakültesi Makine Eğitimi bölümünü tamamlamıştır. Gazi Üniversitesi Fen Bilimleri Enstitüsünden yüksek lisans ve doktora derecelerini almıştır. Halen Gazi Üniversitesi Teknoloji Fakültesi Enerji Sistemleri Mühendisliğinde Profesör Doktor unvanıyla görevini sürdürmektedir. İlgi alanları arasında endüstriyel kurutma sistemleri, havalandırma ve iklimlendirme sistemleri, 1s1 ekonomisi ve ölçme tekniği konuları bulunmaktadır.

\section{Meltem TOKDEMIR}

Meltem Tokdemir, 1989 yılında Ankara'da doğmuştur. 2013 yılında Ankara Üniversitesi Kimya Mühendisliği bölümünde lisans eğitimini tamamlamıştır. 2018 yılında Gazi Üniversitesi Fen Bilimleri Enstitüsü Enerji Sistemleri Mühendisliği bölümünden yüksek lisans derecesini almıştır. İlgi alanları arasında endüstriyel kurutma sistemleri, enerji verimliliği, termodinamik ve $1 \mathrm{~s} 1$ transferi konuları bulunmaktadır. 